\title{
Sludge formation in the activated sludge process with a sludge disintegration unit
}
A. O. M. Alharbi ${ }^{1}$
M. I. Nelson ${ }^{2}$
A. L. Worthy ${ }^{3}$
H. S. Sidhu ${ }^{4}$

(Received 17 December 2013; revised 5 August 2014)

\begin{abstract}
The activated sludge process is one of the major aerobic processes used in the biological treatment of wastewater. A significant drawback of this process is the production of excess 'sludge', the disposal of which can account for $50-60 \%$ of the running costs of a plant. We investigate how the volume and mass of excess sludge produced is reduced by coupling the bioreactor to a sludge disintegration unit.
\end{abstract}

\section{Contents}

\section{Introduction}

http://journal.austms.org.au/ojs/index.php/ANZIAMJ/article/view/7803 gives this article, (c) Austral. Mathematical Soc. 2014. Published August 7, 2014, as part of the Proceedings of the 11th Biennial Engineering Mathematics and Applications Conference. ISSN 1446-8735. (Print two pages per sheet of paper.) Copies of this article must not be made otherwise available on the internet; instead link directly to this URL for this article. 
2 Biochemistry

C350

2.1 Microbial reactions . . . . . . . . . . . . . C350

2.2 The dimensional model . . . . . . . . . . . . . . . . . C352

2.3 The dimensionless model . . . . . . . . . . . . . C354

3 Results

C355

3.1 Steady-state solutions and their stability . . . . . . . C356

3.2 Asymptotic solutions . . . . . . . . . . . . . . C356

4 Discussion

C357

4.1 Sludge formation in the absence of a SDU $(\mathrm{D}=0) \ldots \ldots$ C357

4.2 Sludge formation in the presence of a SDU $(\mathrm{D}>0) \ldots . \quad \ldots$ C357

5 Conclusions

C362

References

C364

A Nomenclature

C364

\section{Introduction}

The activated sludge process (ASP) is the most commonly used method for the aerobic treatment of sewage and industrial wastewater. It contains an aerated bioreactor, where pollutants are degraded by bacteria, and a settling unit, to recycle activated sludge from the effluent stream into the bioreactor.

A product of the ASP is a heterogeneous sludge which must be purged from the system. Traditional methods for its disposal include incineration, landfill disposal and dumping at sea. These methods are becoming increasingly regulated and increasingly expensive. Consequently there is a growing interest in methods that reduce the amount of sludge produced in situ.

The simplest model for the ASP has two variables representing the concen- 


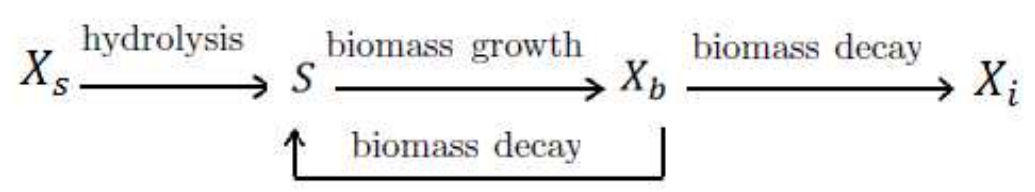

Figure 1: Microbial process in the bioreactor where $\mathrm{S}$ is the soluble substrate, $X_{b}$ is the biomass, $X_{i}$ is the non-biodegradable particulate matter, and $X_{s}$ is the biodegradable particulate substrate.

trations of substrate and biomass [3]. Although this model is widely used to model the effluent concentration from the ASP it does not model sludge formation. An extension of this basic model adds an insoluble substrate component and allows a fraction of dead biomass to be recycled into the pool of insoluble substrate. This is the simplest model for sludge production and was proposed by Chung and Neethling [2].

In earlier work we investigated how the operation of the settling unit influences the amount of sludge formed in the bioreactor [1]. We extend this analysis by investigating how a sludge disintegration unit (SDU) is used to control the amount of sludge within the bioreactor.

\section{Biochemistry}

\subsection{Microbial reactions}

Figure 1 provides a schematic of the three biochemical processes in the model. The first biochemical process is the hydrolysis of biodegradable particulate substrate $X_{s}$ to produce soluble substrate $S$ :

$$
X_{s} \stackrel{k_{h}}{\longrightarrow} \alpha_{h} S,
$$

where $\alpha_{h}$ is the yield factor for hydrolysis of insoluble organic compounds. The second biochemical process is the use of soluble organic materials $S$ as a 


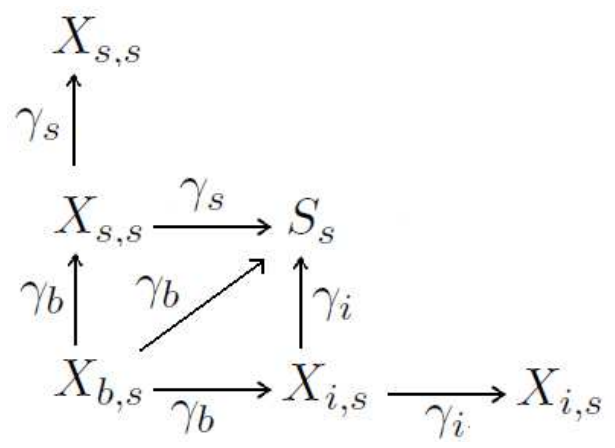

Figure 2: Disintegration processes occurring within the SDU. Nomenclature is provided in the text.

substrate for energy and growth by the biomass $X_{b}$ :

$$
S \stackrel{\mu(S)}{\longrightarrow} \alpha_{g} X_{b}
$$

where $\alpha_{g}$ is the yield factor for growth of biomass. The final biochemical process is the death of biomass which adds to the pool of soluble substrate $S$ and produces an inert residue $X_{i}$ :

$$
x_{b} \stackrel{k_{d}}{\longrightarrow} f_{i} X_{i}+f_{s} \alpha_{s} S,
$$

where $f_{i}$ is the fraction of dead biomass converted to inert material, $f_{s}$ is the fraction of dead biomass converted to soluble substrate, and $\alpha_{\mathrm{s}}$ is the yield factor for conversion of dead biomass to soluble substrate. We assume that $f_{i}+f_{s}=1$. Mass conservation imposes the restriction $0<f_{s} \alpha_{g} \alpha_{s} \leqslant 1$.

Figure 2 shows the three disintegration reactions that occur within the SDU. The subscript $s$ denotes a concentration inside the SDU. The first disintegration process is the conversion of biomass $X_{b, s}$ into non-biodegradable particulate $X_{i, s}$, biodegradable particulate substrate $X_{s, s}$ and soluble substrate $S_{s}$ :

$$
X_{b, s} \stackrel{\gamma_{b}}{\longrightarrow} f_{p, s} X_{i, s}+\left(1-\alpha-f_{p, s}\right) X_{s, s}+\alpha \alpha_{s} s_{s},
$$


where $\alpha$ is the solubilization efficiency of the SDU, $\alpha_{\mathrm{s}}$ is the yield factor for conversion of dead biomass to soluble substrate, $f_{p, s}$ is the fraction of dead biomass converted to inert material in the SDU, $\gamma_{\mathrm{b}}$ is the disintegration rate of biomass, and $0 \leqslant \alpha \leqslant 1-f_{p, s}$. The second disintegration process is the conversion of biodegradable particulate substrate $X_{s, s}$ into soluble substrate $S_{s}$ and biodegradable particulate substrate $X_{s, s}$ :

$$
X_{s, s} \stackrel{\gamma_{s}}{\longrightarrow} \alpha \alpha_{h} S_{s}+(1-\alpha) X_{s, s},
$$

where $\alpha_{h}$ is the yield factor for hydrolysis of insoluble substrate, and $\gamma_{s}$ is the disintegration rate of biodegradable particulate substrate. The third disintegration process is the conversion of non-biodegradable particulate substrate $X_{i, s}$ into soluble substrate $S_{s}$ and non-biodegradable particulate substrate $X_{i, s}$ :

$$
X_{i, s} \stackrel{\gamma_{i}}{\rightarrow} \beta_{i} \alpha_{\text {SDU }} S_{s}+\left(1-\beta_{i}\right) X_{i, s},
$$

where $\beta_{i}$ is the conversion efficiency from non-biodegradable particulates to readily biodegradable (soluble) substrate, $\alpha_{\mathrm{SDU}}$ is a yield factor for the conversion of inert material to soluble substrate through disintegration, and $\gamma_{i}$ is the disintegration rate of non-biodegradable particulate substrate.

\subsection{The dimensional model}

We first provide all model equations in the bioreactor. All parameters are defined in Appendix A. The rate of change in the concentration of soluble substrate is

$$
\frac{d S}{d t}=\frac{F}{V}\left(S_{0}-S\right)+\frac{F}{V} D\left(S_{s}-S\right)+\alpha_{h} k_{h} X_{s}+f_{s} \alpha_{s} k_{d} X_{b}-\frac{X_{b} \mu(S)}{\alpha_{g}} .
$$

The rate of change in the concentration of biomass is

$$
\frac{d X_{b}}{d t}=-\frac{F}{V} X_{b}+\frac{F}{V} R(C-1) X_{b}+\frac{F}{V} D\left(X_{b, s}-X_{b}\right)+X_{b} \mu(S)-k_{d} X_{b}
$$


The rate of change in the concentration of non-biodegradable particulate material is

$$
\frac{d X_{i}}{d t}=\frac{F}{V}\left(X_{i, 0}-X_{i}\right)+\frac{F}{V} R(C-1) X_{i}+\frac{F}{V} D\left(X_{i, s}-X_{i}\right)+f_{i} k_{d} X_{b} .
$$

The rate of change in the concentration of biodegradable particulate substrate is

$$
\frac{d X_{s}}{d t}=\frac{F}{V}\left(X_{s, 0}-X_{s}\right)+\frac{F}{V} R(C-1) X_{s}+\frac{F}{V} D\left(X_{s, s}-X_{s}\right)-k_{h} X_{s} .
$$

The specific growth rate is

$$
\mu(S)=\frac{\mu_{m} S}{K_{s}+S}
$$

The residence time is

$$
\tau=\frac{\mathrm{V}}{\mathrm{F}} .
$$

The chemical demand oxygen characterises the organic carbon content of wastewaters:

$$
\mathrm{COD}=\mathrm{S}+\alpha_{\mathrm{h}} \mathrm{X}_{\mathrm{s}}
$$

The total volatile suspended solids represents the solid organic carbon in the sludge:

$$
\text { VSS }=X_{t}=X_{b}+X_{i}+X_{s} .
$$

In practice, a target value for the vSs is set. We set the target value to $\mathrm{VSS}_{\mathrm{t}}=12000 \mathrm{mg} \mathrm{L}^{-1}[4]$.

We now provide all model equations in the sludge disintegration unit. Again, all parameters are defined in Appendix A. The rate of change in the concentration of soluble substrate is

$$
\frac{\mathrm{d} S_{s}}{d t}=\frac{F}{V_{s}} D\left(S-S_{s}\right)+\alpha \alpha_{s} \gamma_{b} X_{b, s}+\alpha \alpha_{h} \gamma_{s} X_{s, s}+\beta_{i} \alpha_{s D u} \gamma_{i} X_{i, s}
$$

The rate of change in the concentration of biomass is

$$
\frac{d X_{b, s}}{d t}=\frac{F}{V_{s}} D\left(X_{b}-X_{b, s}\right)-\gamma_{b} X_{b, s} .
$$


The rate of change in the concentration of non-biodegradable particulate material is

$$
\frac{d X_{i, s}}{d t}=\frac{F}{V_{s}} D\left(X_{i}-X_{i, s}\right)+f_{p, s} \gamma_{b} X_{b, s}-\beta_{i} \gamma_{i} X_{i, s}
$$

The rate of change in the concentration of biodegradable particulate substrate is

$$
\frac{d X_{s, s}}{d t}=\frac{F}{V_{s}} D\left(X_{s}-X_{s, s}\right)+\left(1-\alpha-f_{p, s}\right) \gamma_{b} X_{b, s}-\alpha \gamma_{s} X_{s, s}
$$

The most important parameter associated with the SDU is the sludge disintegration factor D.

\subsection{The dimensionless model}

By introducing dimensionless variables for time and concentrations of the substrate, microorganism and particulates, the model equations are written in dimensionless form. An asterisk superscript indicates a dimensionless variable. The dimensionless equations which model the reactor are

$$
\begin{aligned}
\frac{d S^{*}}{d t^{*}}= & \frac{1}{\tau^{*}}\left(S_{0}^{*}-S^{*}\right)+\frac{D}{\tau^{*}}\left(S_{s}^{*}-S^{*}\right)+\alpha_{g h} k_{h}^{*} X_{s}^{*}+f_{s} \alpha_{g s} k_{d}^{*} X_{b}^{*} \\
& -\frac{S^{*} X_{b}^{*}}{1+S^{*}}, \\
\frac{d X_{b}^{*}}{d t^{*}}= & \frac{-1}{\tau^{*}} X_{b}^{*}+\frac{R^{*}}{\tau^{*}} X_{b}^{*}+\frac{D}{\tau^{*}}\left(X_{b, s}^{*}-X_{b}^{*}\right)+\frac{X_{b}^{*} S^{*}}{1+S^{*}}-k_{d}^{*} X_{b}^{*}, \\
\frac{d X_{i}^{*}}{d t^{*}}= & \frac{1}{\tau^{*}}\left(X_{i, 0}^{*}-X_{i}^{*}\right)+\frac{R^{*}}{\tau^{*}} X_{i}^{*}+\frac{D}{\tau^{*}}\left(X_{i, s}^{*}-X_{i}^{*}\right)+f_{i} k_{d}^{*} X_{b}^{*}, \\
\frac{d X_{s}^{*}}{d t^{*}}= & \frac{1}{\tau^{*}}\left(X_{s, 0}^{*}-X_{s}^{*}\right)+\frac{R^{*}}{\tau^{*}} X_{s}^{*}+\frac{D}{\tau^{*}}\left(X_{s, s}^{*}-X_{s}^{*}\right)-k_{h}^{*} X_{s}^{*} .
\end{aligned}
$$

In addition,

$$
\mathrm{COD}^{*}=\mathrm{S}^{*}+\alpha_{\mathrm{g}, \mathrm{h}} \mathrm{X}_{\mathrm{s}}^{*} \text { and } \quad \mathrm{VSS}^{*}=\mathrm{X}_{\mathrm{b}}^{*}+\mathrm{X}_{\mathrm{i}}^{*}+\mathrm{X}_{\mathrm{s}}^{*} .
$$


The equations which model the sludge disintegration unit are

$$
\begin{aligned}
\frac{d S_{s}^{*}}{d t^{*}} & =\frac{D V^{*}}{\tau^{*}}\left(S^{*}-S_{s}^{*}\right)+\alpha \alpha_{g s} \gamma_{b}^{*} X_{b, s}^{*}+\alpha \alpha_{g h} \gamma_{s}^{*} X_{s, s}^{*}+\beta_{i} \alpha \alpha_{g s D u} \gamma_{i}^{*} X_{i, s}^{*}, \\
\frac{d X_{b, s}^{*}}{d t^{*}} & =\frac{D V^{*}}{\tau^{*}}\left(X_{b}^{*}-X_{b, s}^{*}\right)-\gamma_{b}^{*} X_{b, s}^{*}, \\
\frac{d X_{i, s}^{*}}{d t^{*}} & =\frac{D V^{*}}{\tau^{*}}\left(X_{i}^{*}-X_{i, s}^{*}\right)+f_{p, s} \gamma_{b}^{*} X_{b, s}^{*}-\beta_{i} \gamma_{i}^{*} X_{i, s}^{*}, \\
\frac{d X_{s, s}^{*}}{d t^{*}} & =\frac{D V^{*}}{\tau^{*}}\left(X_{s}^{*}-X_{s, s}^{*}\right)+\left(1-\alpha-f_{p, s}\right) \gamma_{b}^{*} X_{b, s}^{*}-\alpha \gamma_{s}^{*} X_{s, s}^{*}
\end{aligned}
$$

The target value for vss* is

$$
\mathrm{VSS}_{\mathrm{t}}^{*}=\frac{\mathrm{VSS}_{\mathrm{t}}}{\alpha_{\mathrm{g}} \mathrm{k}_{\mathrm{s}}}=\frac{12000}{\alpha_{\mathrm{g}} \mathrm{k}_{\mathrm{s}}}=77.071 .
$$

\section{Results}

Alharbi et al. [1] found the steady-state solutions of the ASP without a SDU, equations (16)-(19) with $\mathrm{D}=0$, and their stability was determined as a function of the residence time $\tau^{*}$. These solutions were used to investigate the steady-sludge VSS concentration as a function of the operation of the settling unit through the effective recycle parameter $R^{*}$, constrained by $0 \leqslant R^{*} \leqslant 1$.

We assume that the disintegration processes in the SDU are much quicker than the biochemical processes within the bioreactor so that the SDU effectively operates at steady-state. This reduces the ASP-SDU model to four differential equations for the ASP and four algebraic equations for the SDU. As the steady-state solution within the SDU is readily found, the ASP-SDU model reduces to four non-linear differential equations. 


\subsection{Steady-state solutions and their stability}

The steady-state solution within the SDU is comprised of two branches: a washout solution branch representing process failure where $X_{\mathrm{b}}^{*}=0$; and a no-washout branch where $X_{b}^{*} \neq 0$. The lengthy expressions for these solution branches are omitted. The stability of both solution branches must be determined numerically.

\subsection{Asymptotic solutions}

At large residence times along the no-washout (NW) branch

$$
\begin{aligned}
& \mathrm{S}_{\mathrm{NW}}^{*} \approx \frac{k_{\mathrm{d}}^{*}}{1-\mathrm{k}_{\mathrm{d}}^{*}}+\frac{1-\mathrm{R}^{*}+\mathrm{D}}{\left(\mathrm{k}_{\mathrm{d}}^{*}-1\right)^{2} \tau^{*}}+\mathcal{O}\left(\frac{1}{\tau^{* 2}}\right), \\
& X_{\mathrm{b}, \mathrm{NW}}^{*} \approx \frac{\mathrm{a}_{0}}{\tau^{*}}+\mathcal{O}\left(\frac{1}{\tau^{* 2}}\right) \text {, } \\
& X_{i}^{*} \approx \frac{X_{i, 0}^{*}}{1-R^{*}+D}+\frac{f_{i} k_{d}^{*} a_{0}}{1-R^{*}+D}+\frac{a_{1}}{\tau^{*}}+\mathcal{O}\left(\frac{1}{\tau^{* 2}}\right), \\
& X_{s}^{*} \approx \frac{X_{s, 0}^{*}}{k_{h}^{*} \tau^{*}}+\mathcal{O}\left(\frac{1}{\tau^{* 2}}\right) \text {, } \\
& \mathrm{COD}_{\mathrm{Nw}}^{*} \approx \frac{k_{\mathrm{d}}^{*}}{1-k_{\mathrm{d}}^{*}}+\left(\frac{1-\mathrm{R}^{*}+\mathrm{D}}{\left(k_{\mathrm{d}}^{*}-1\right)^{2}}+\frac{\alpha_{\mathrm{gh}} X_{\mathrm{s}, 0}^{*}}{k_{\mathrm{h}}^{*}}\right) \frac{1}{\tau^{*}}+\mathcal{O}\left(\frac{1}{\tau^{* 2}}\right) \text {, } \\
& \mathrm{VSS}_{\mathrm{NW}}^{*} \approx \frac{X_{i, 0}^{*}+\mathrm{f}_{i} k_{\mathrm{d}}^{*} \mathrm{a}_{0}}{1-\mathrm{R}^{*}+\mathrm{D}}+\left(\mathrm{a}_{0}+\mathrm{a}_{1}+\frac{X_{\mathrm{s}, 0}^{*}}{k_{\mathrm{h}}^{*}}\right) \frac{1}{\tau^{*}}+\mathcal{O}\left(\frac{1}{\tau^{* 2}}\right) .
\end{aligned}
$$

where

$$
\begin{aligned}
& a_{0}=\frac{\left(1-k_{d}^{*}\right) b_{0}-k_{d}^{*}\left(1-R^{*}+D\right)}{k_{d}^{*}\left(1-k_{d}^{*}\right)\left[\left(1-R^{*}+D\right)\left(1-f_{s} \alpha_{g s}\right)-D \alpha \alpha_{g S D U} f_{i}\right]}, \\
& b_{0}=D \alpha \alpha_{g S D U} X_{i, 0}^{*}+\left(1-R^{*}+D\right)\left(\alpha_{g h} X_{s, 0}^{*}+S_{0}^{*}\right) .
\end{aligned}
$$

The expression for $a_{1}$ is not included due to its length. It is independent of the disintegration rate $\gamma_{i}$. 


\section{Discussion}

We consider the case when the disintegration rates in the biomass, biodegradable particulate and non-biodegradable particulate are equal: $\gamma_{j}=\gamma$ for $j=i, b, s$; and investigate the effect of the SDU on sludge formation.

\subsection{Sludge formation in the absence of a $\operatorname{SDU}(\mathrm{D}=0)$}

The accumulation of sludge in the ASP in the absence of a SDU was investigated by Alharbi et al. [1]. There are five generic steady-state response diagrams for the sludge content as a function of the residence time $\tau^{*}$ as the effective recycle parameter $R^{*}$ is varied. For the first four cases there is a critical value of the residence time $\tau_{\text {sludge }}^{*}$ such that if $\tau^{*}>\tau_{\text {sludge }}^{*}$, then the steady-state value of the volatile suspended solids is always below the target value. These cases are highly desirable, but are rarely achieved in practice.

For high values of the effective recycle parameter, $0.7387 \leqslant R^{*} \leqslant 1$, the response diagram is shown in Figure 3 (case five). The steady-state sludge content is always higher than the target value $\mathrm{VSS}_{\mathrm{t}}^{*}$. This is undesirable.

\subsection{Sludge formation in the presence of a SDU $(\mathrm{D}>0)$}

This section concentrates on how the operation of the SDU effects the steadystate diagram for 'case five'. In this case the sludge content is above the target value for any value of the residence time.

Figures 4 and 5 shows the steady-state sludge content over time, for different decay rates $\gamma$ and for two values of the effective recycle ratio $R^{*}$. In Figure 4 where $R^{*}=0.6$, as the disintegration rate $\gamma$ increases the steady-state diagram transitions into case four. In Figure 5 where $R^{*}=0.9$, the SDU is less successful than when $R^{*}=0.6$. Although the amount of sludge within 


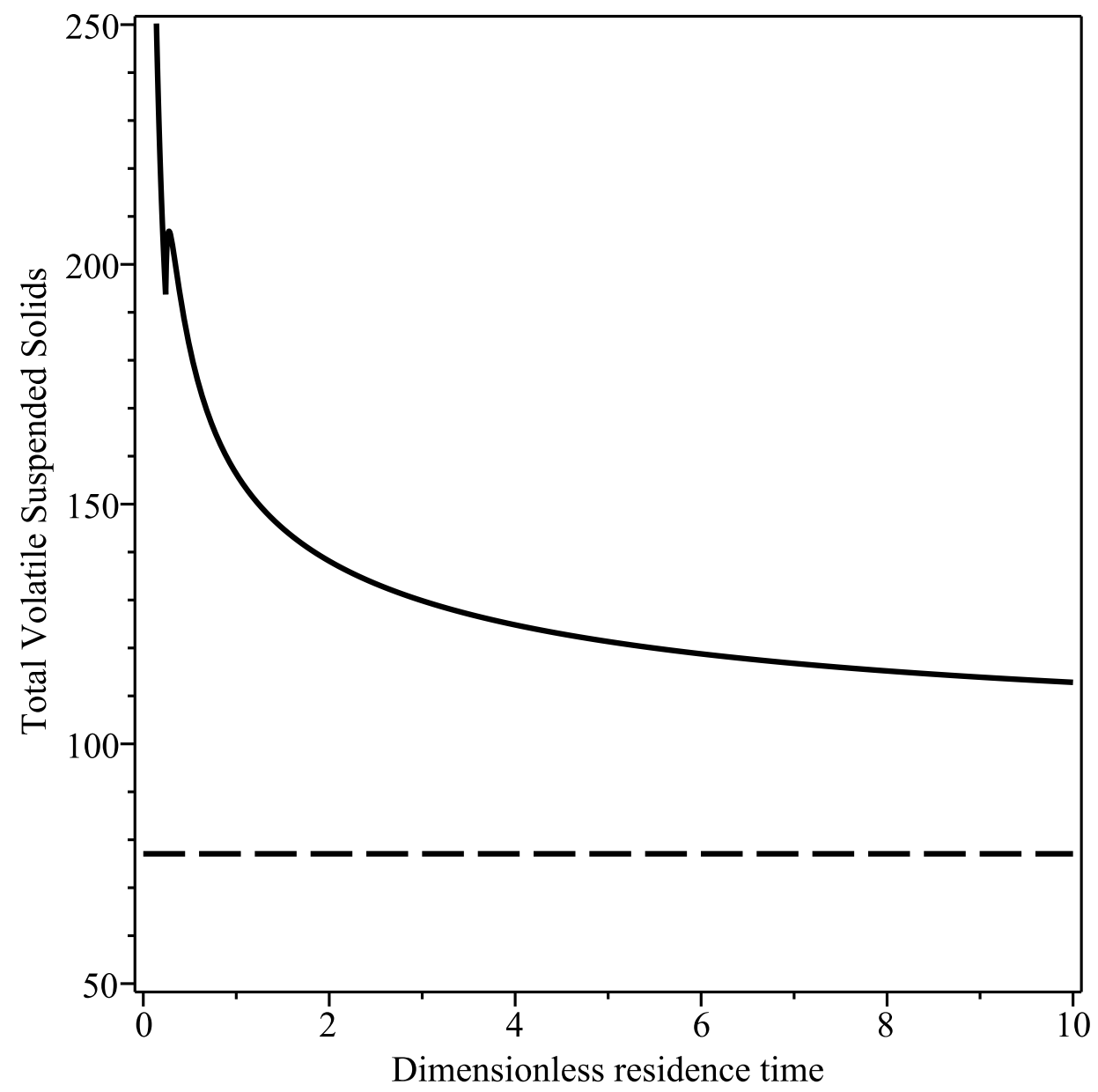

Figure 3: Steady state diagram for the volatile suspended solids (case 5) in the absence of a SDU with $\mathrm{R}^{*}=0.8$. The horizontal line denotes the target value of the volatile suspended solids $\mathrm{VSS}_{\mathrm{t}}^{*}$. 
the bioreactor is reduced as the disintegration rate increases, the response diagram remains 'case five'.

When there is no SDU the transition from case four to case five occurs when the effective recycle ratio is $R_{45}^{*}=0.7387$. Our numerical investigation revealed the operation of a SDU increases this transition value. We found the transition value to be independent of the scaled volume of the SDU $\mathrm{V}^{*}$ and the disintegration rate $\gamma$. For the parameter values used in Figures 4 and 5 $(D=0.1)$ the transition value is $R_{45}^{*}=0.8385$. Thus the SDU allows higher values of the effective recycle parameter without the production of excess sludge. In Figure 5 the effective recycle parameter $R^{*}=0.9$ is higher than the new critical value $R_{45}^{*}=0.8385$.

The transition value $R_{45}^{*}$ is determined from the vSS value in the limit of infinite residence time. Equation (31) show that this value is independent of the sludge disintegration rates, $\gamma_{b}, \gamma_{i}$ and $\gamma_{s}$, and the conversion efficiency $\beta_{i}$; it depends upon D, $\alpha$ and $\alpha_{\text {gSDu }}$. Only the sludge disintegration factor D can be changed. From equation (31) the VSS at infinity is equal to the target value when

$$
\mathrm{Q}(\mathrm{D})=\mathrm{a}_{\mathrm{D}} \mathrm{D}^{2}+\mathrm{b}_{\mathrm{D}} \mathrm{D}+\mathrm{c}_{\mathrm{D}}=0,
$$

where the coefficients are

$$
\begin{aligned}
a_{D}= & -v_{S S}^{*}\left(1-k_{d}^{*}\right)\left(1-\alpha \alpha_{g s D u} f_{i}-f_{s} \alpha_{g s}\right) \leqslant 0 \\
b_{D}= & \left(1-k_{d}^{*}\right)\left\{\left(1-f_{s} \alpha_{g s}\right) X_{i, 0}^{*}+\left(\alpha_{g h} X_{s, 0}^{*}+S_{0}^{*}\right) f_{i}\right. \\
& \left.-\operatorname{vSS}_{t}^{*}\left(1-R^{*}\right)\left[2\left(1-f_{s} \alpha_{g s}\right)-\alpha \alpha_{g s D u} f_{i}\right]\right\}-f_{i} k_{d}^{*} \\
c_{D}= & \left(1-R^{*}\right)\left(( 1 - k _ { d } ^ { * } ) \left\{\left(1-f_{s} \alpha_{g s}\right)\left[X_{i, 0}^{*}-v S_{t}^{*}\left(1-R^{*}\right)\right]\right.\right. \\
& \left.\left.+\left(\alpha_{g h} X_{s, 0}^{*}+S_{0}^{*}\right) f_{i}\right\}-f_{i} k_{d}^{*}\right) .
\end{aligned}
$$

When $\mathrm{D}=0$ [1] we have $\mathrm{R}_{1}^{*}=1$ and

$$
R_{2}^{*}=\frac{\left(1-k_{d}^{*}\right)\left[\left(1-f_{s} \alpha_{g s}\right)\left(v S_{t}^{*}-X_{i, 0}^{*}\right)-\left(\alpha_{g h} X_{s, 0}^{*}+S_{0}^{*}\right) f_{i}\right]+f_{i} k_{d}^{*}}{\left(1-k_{d}^{*}\right)\left(1-f_{s} \alpha_{g s}\right) \operatorname{vSS}_{t}^{*}}
$$




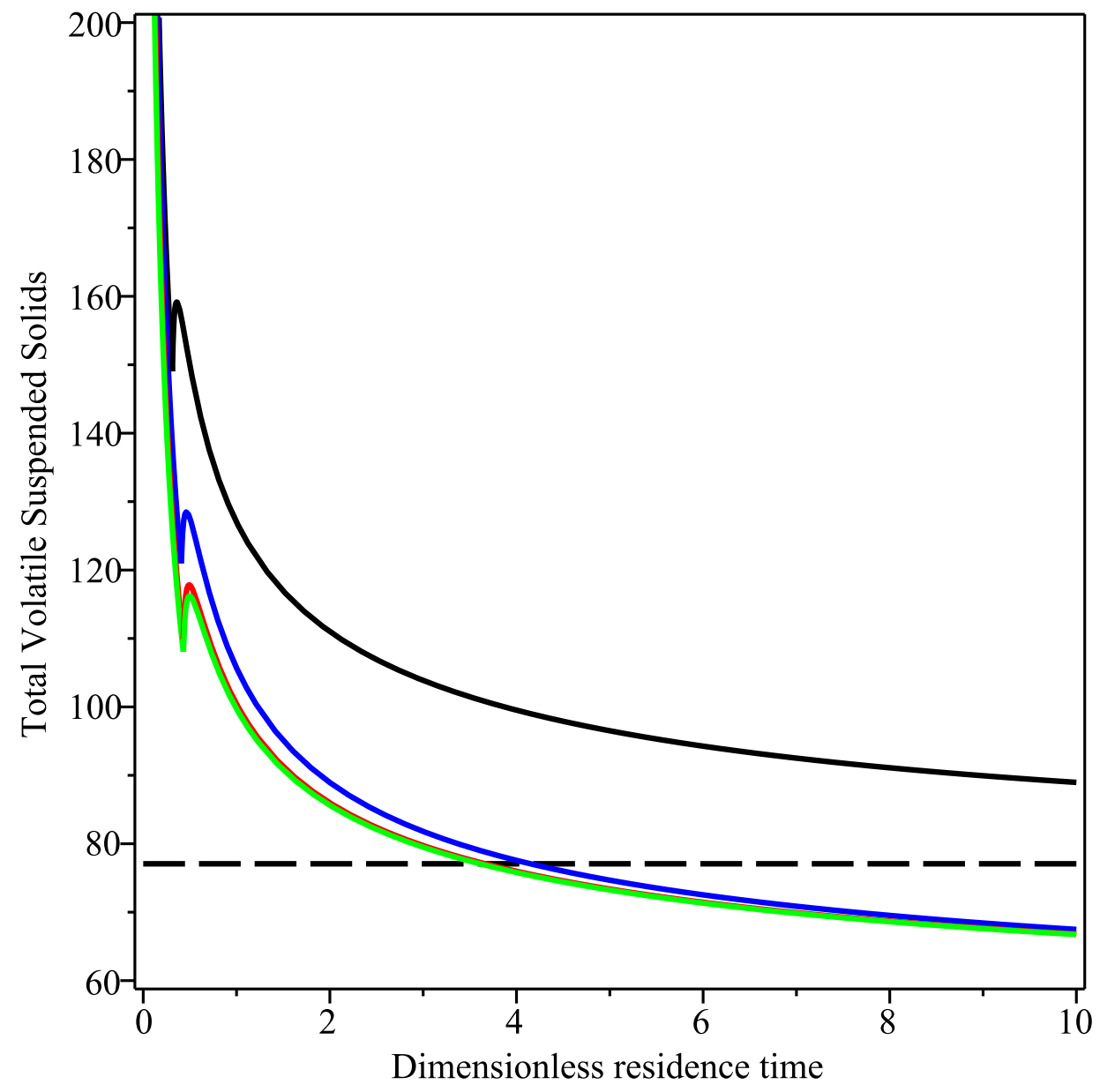

Figure 4: The volatile suspended solids concentration as a function of the residence time. Parameter values are $\mathrm{D}=0.1, \mathrm{~V}^{*}=1, \mathrm{R}^{*}=0.6$ and $\gamma=0,0.1,1,10$ for black, blue, red and green, respectively. 


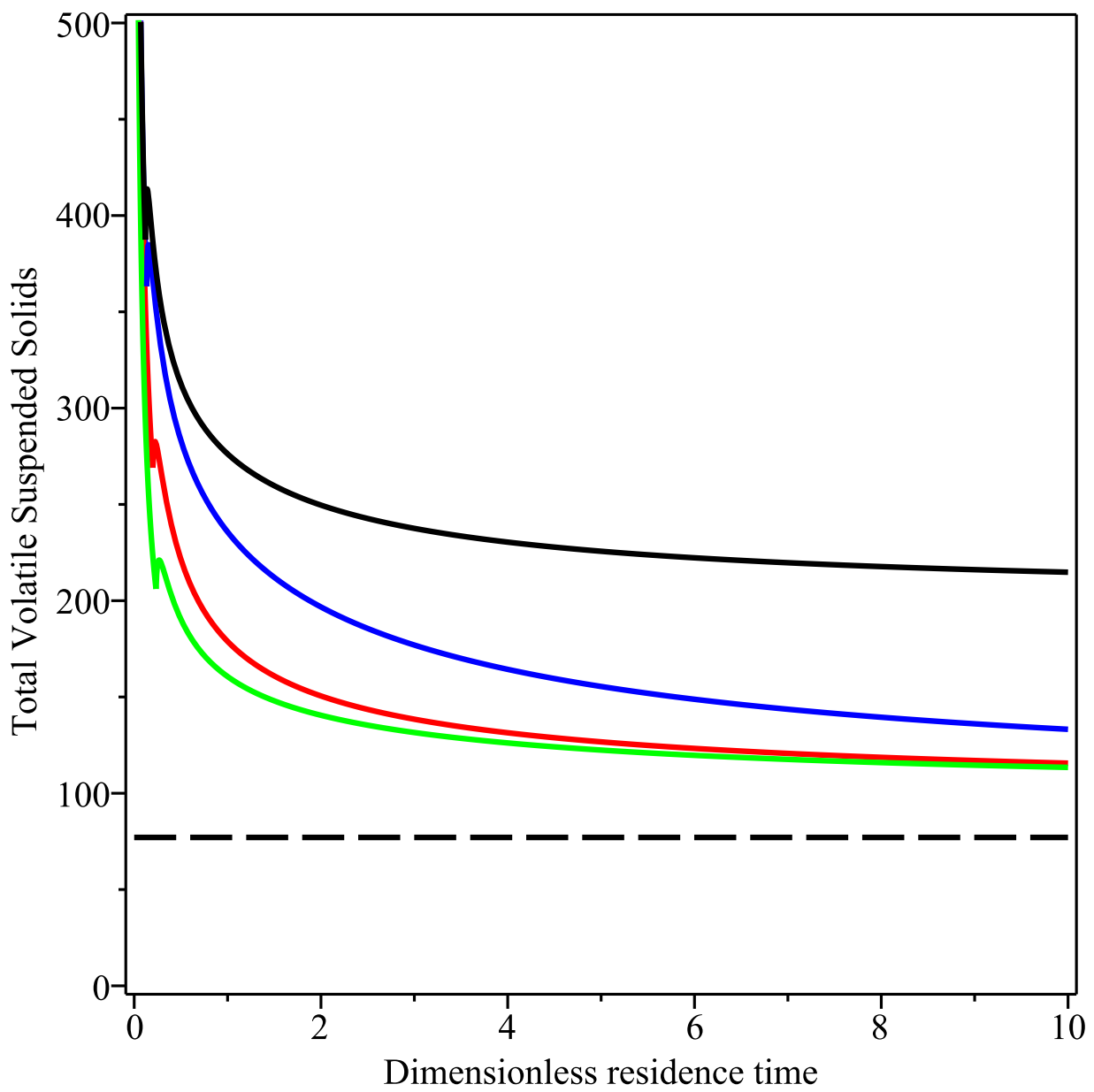

Figure 5: The volatile suspended solids concentration as a function of the residence time. Parameter values are $\mathrm{D}=0.1, \mathrm{~V}^{*}=1, \mathrm{R}^{*}=0.9$ and $\gamma=0,0.1,0.35,10$ for black, blue, red and green, respectively. For $1 \leqslant \gamma \leqslant 10$ plots are visually indistinguishable. 
When $\mathrm{R}^{*}=1$ we have, from equation (34), $\mathrm{D}_{1}=0$ and

$$
D_{2}=\frac{\left(1-k_{d}^{*}\right)\left[\left(1-f_{s} \alpha_{g s}\right) X_{i, 0}^{*}+\left(\alpha_{g h} X_{s, 0}^{*}+S_{0}^{*}\right) f_{i}\right]-f_{i} k_{d}^{*}}{\operatorname{VSS}_{t}^{*}\left(1-k_{d}^{*}\right)\left(1-\alpha \alpha_{g s D} f_{i}-f_{s} \alpha_{g s}\right)} .
$$

Figure 6 plots equation (34). To the left of the line is the desirable region where the VSS at infinite residence time is smaller than the target value. To the right of the line the vSS at infinite residence time is larger than the target value. In the former region, as the disintegration rate $\gamma$ is increased from zero, transitions in the steady-state diagram occur, similar to Figure 4. In the latter region, the amount of sludge formed decreases as the disintegration rate increases. However, the steady-state diagram is always 'case five', similar to Figure 5.

It is surprising that the curve defined by equation (34), a quadratic equation, is a straight line. However, examination of the discriminant of the quadratic equation (34) reveals that it is essentially independent of the effective recycle parameter over the range $0 \leqslant R^{*} \leqslant 1$. It then follows that there is a linear relationship between the sludge disintegration factor $\mathrm{D}$ and the effective recycle parameter $R^{*}$.

\section{Conclusions}

We extended a model for sludge formation in the activated sludge process [1] to include a sludge disintegration unit. As the disintegration rate $\gamma$ increases the amount of sludge in the bioreactor decreases. Two forms of behaviour are found as the disintegration rate is increased, see Figures 4 and 5. The transition between the two behaviours is governed by the vss value when the residence time is infinite. This is independent of the disintegration rate $\gamma$. For a fixed value of the effective recycle parameter $R^{*}$ there is a critical value of the sludge disintegration factor $\mathrm{D}$. If $\mathrm{D}$ is sufficiently high, then the sludge content is below the target value for sufficiently large values of the residence 


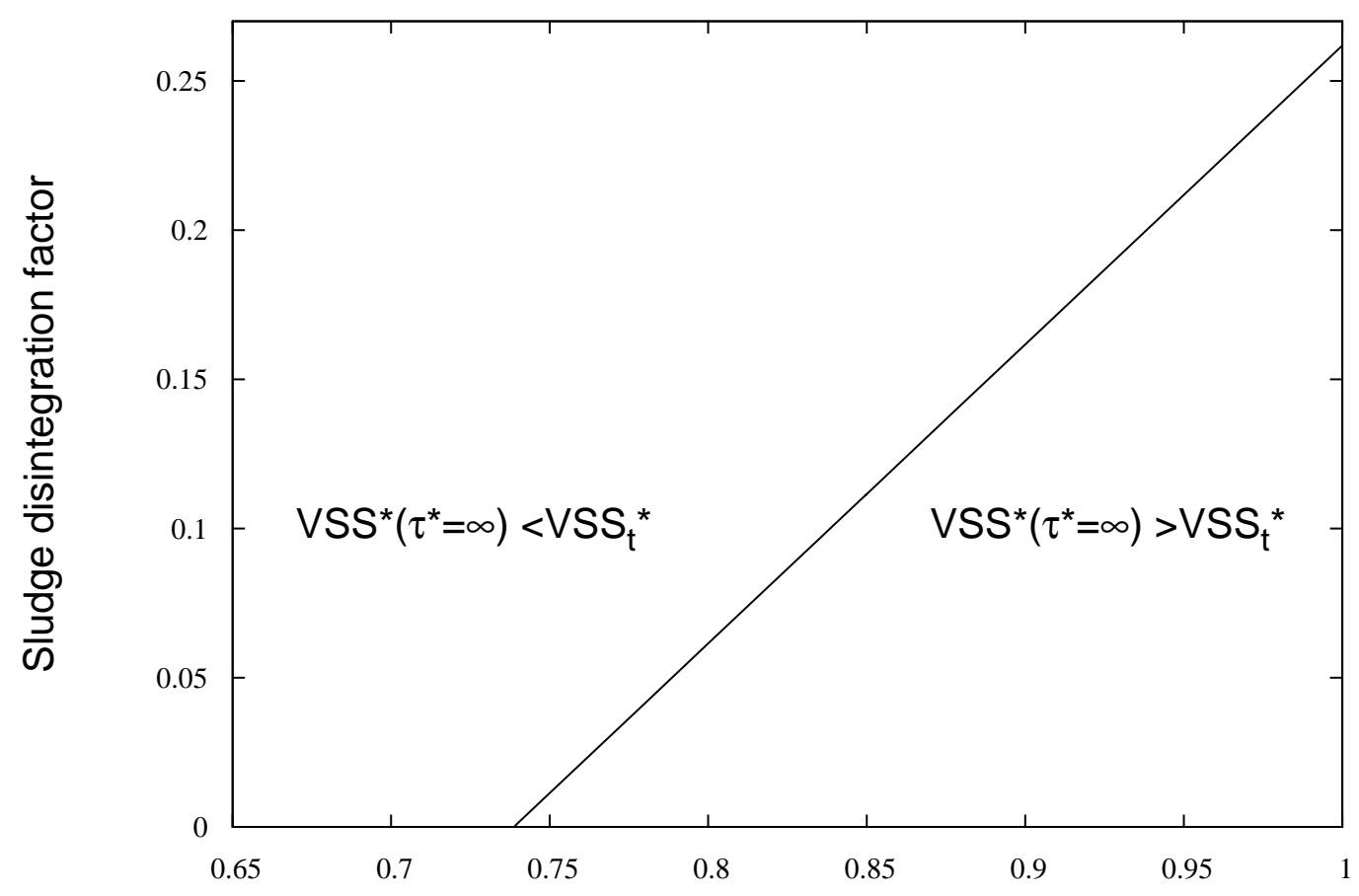

\section{Effective recycle parameter}

Figure 6: The transition between the behaviour shown in Figures 4 and 5 as a function of the effective recycle parameter $R^{*}$ and the sludge disintegration factor $\mathrm{D}$ when $\mathrm{V}^{*}=1$. This transition is governed by equation (34).

time. If $\mathrm{D}$ is below the critical value, then the the sludge content is always above the target value.

In future work we aim to comprehensively analyse the behaviour of the activated sludge process for finite values of the disintegration rate $\gamma$.

Acknowledgements AA is grateful to the High Education Ministry of Saudi Arabia for a PhD scholarship. The authors thank the copyeditor for careful reading of our manuscript. 


\section{References}

[1] A. O. M. Alharbi, M. I. Nelson, A. L. Worthy, and H. S. Sidhu. Sludge formation in the activated sludge process: Mathematical analysis. In Proc. Australasian Chem. Eng. Conf., Chemeca 2013. Chemical College, Engineers Australia, 2013.

www.conference.net.au/chemeca2013/papers/29490.pdf C350, C355, C357, C359, C362

[2] Y.-C. Chung and J. B. Neethling. Viability of anaerobic digester sludge. J. Environ. Eng., 116(2):330-342, 1990. doi:10.1061/(ASCE)0733-9372(1990)116:2(330) C350, C366

[3] M. I. Nelson, T. Kerr, and X. D. Chen. A fundamental analysis of continuous flow bioreactor and membrane reactor models with death and maintenance included. Asia-Pac. J. Chem. Eng., 3:70-80, 2008. doi:10.1002/apj.106 C350

[4] S.-H. Yoon. Important operational parameters of membrane bioreactor-sludge disintegration (MBR-SD) system for zero excess sludge production. Water Res., 37(8):1921-1931, 2003. doi:10.1016/S0043-1354(02)00578-X C353

\section{A Nomenclature}

Here we provide definitions and typical units for all parameters. We denote the units of soluble substrate by $|S|$ and the units of biomass, non-biodegradable particulate matter and biodegradable particulate substrate by $|X|$. Typical units are $|\mathrm{S}|=(\mathrm{mg} \mathrm{COD}) \mathrm{L}^{-1}$ and $|\mathrm{X}|=(\mathrm{mg} \mathrm{VSS}) \mathrm{L}^{-1}$.
C
Recycle concentration factor
COD
Chemical oxygen demand
D
Sludge disintegration factor 
F

$\mathrm{K}_{\mathrm{S}}$

$\mathrm{R}$

$S$

$\mathrm{S}_{\mathrm{S}}$

$\mathrm{S}_{0}$

$S_{\mathrm{k}}^{*}=S_{\mathrm{k}} / S_{0}$

$\mathrm{V}$

$V_{s}$

$\mathrm{V}^{*}=\mathrm{V} / \mathrm{V}_{\mathrm{s}}$

$X_{\mathrm{b}}$

$x_{b, s}$

$X_{i}$

$X_{i, s}$

$X_{s}$

$X_{s, s}$

$\mathrm{X}_{\mathrm{j}, 0}$

$x_{t}$

$X_{k}^{*}=X_{k} /\left(\alpha_{g} K_{s}\right)$

$k_{\mathrm{d}}$

$k_{d}^{*}=k_{d} / \mu_{m}$

$k_{h}$

$k_{h}^{*}=k_{h} / \mu_{m}$

$f_{s}$

$f_{i}$

t
Bioreactor flow rate

Monod constant

Recycle ratio

Substrate concentration in bioreactor

Substrate concentration in SDU

Substrate concentration in feed

Dimensionless substrate concentration

Bioreactor volume

SDU volume

Scaled SDU reactor volume

Biomass concentration in bioreactor

Biomass concentration in SDU

Concentration of non-biodegradable particulate materials in bioreactor

Concentration of non-biodegradable particulate materials in SDU

Concentration of biodegradable particulate substrate in bioreactor

Concentration of biodegradable particulate substrate in SDU

Feed concentration $(j=b, i, s)$

Total biomass concentration

Dimensionless concentration

Death coefficient

Dimensionless death coefficient

Hydrolysis rate of insoluble organic compounds

Dimensionless hydrolysis rate

Fraction of dead biomass converted to soluble substrate

Fraction of dead biomass converted to inert material

Time $\left(\mathrm{dm}^{3} \mathrm{hr}^{-1}\right)$

$(|\mathrm{S}|)$

(-)

$(|S|)$

$(|\mathrm{S}|)$

$(|\mathrm{S}|)$

(-)

$\left(\mathrm{dm}^{3}\right)$

$\left(\mathrm{dm}^{3}\right)$

(-)

$(|X|)$

$(|X|)$

$(|X|)$

$(|X|)$

$(|X|)$

$(|X|)$

(-)

$\left(\mathrm{hr}^{-1}\right)$

(-)

$\left(h r^{-1}\right)$

(-)

$\left(h r^{-1}\right)$ 


$\begin{array}{lll}\mathrm{t}^{*}=\mu_{\mathrm{m}} \mathrm{t} & \text { Dimensionless time } & (-) \\ \alpha_{\mathrm{g}} & \text { Yield factor for growth of biomass } & \left(|\mathrm{X} \| \mathrm{S}|^{-1}\right) \\ \alpha_{\mathrm{gSDU}}=\alpha_{\mathrm{g}} \alpha_{\mathrm{SDU}} & \text { Dimensionless yield coefficient in SDU } & (-) \\ \alpha_{\mathrm{gh}}=\alpha_{\mathrm{h}} \alpha_{\mathrm{g}} & \text { Dimensionless yield coefficient in bioreactor } & (-) \\ \alpha_{\mathrm{gs}}=\alpha_{\mathrm{g}} \alpha_{\mathrm{s}} & \text { Dimensionless yield coefficient in bioreactor } & (-) \\ \alpha_{\mathrm{h}} & \text { Yield factor for hydrolysis of insoluble organic } & \left(|\mathrm{S} \| \mathrm{X}|^{-1}\right) \\ & \text { compounds } & \\ \alpha_{\mathrm{s}} & \text { Yield factor: conversion of dead biomass to } & \left(|\mathrm{S} \| \mathrm{X}|^{-1}\right) \\ & \text { Soluble substrate } & \\ \gamma_{\mathrm{b}} & \text { Disintegration rate of biomass in sDU } & \left(\mathrm{hr}^{-1}\right) \\ \gamma_{\mathrm{i}} & \text { Disintegration rate of non-biodegradable par- } & \left(\mathrm{hr}^{-1}\right) \\ & \text { ticulate substrate in SDU } & \\ \gamma_{\mathrm{s}} & \text { Disintegration rate of biodegradable particu- } & \left(\mathrm{hr}^{-1}\right) \\ \gamma_{\mathrm{k}}^{*}=\gamma_{\mathrm{k}} / \mu_{\mathrm{m}} & \text { late substrate in sDU } & \\ \mu(S) & \text { Dimensionless disintegration rate }(\mathrm{k}=\mathrm{b}, \mathrm{i}, \mathrm{s}) & (-) \\ \mu_{\mathrm{m}} & \text { Specific growth rate model } & \left(\mathrm{hr}^{-1}\right) \\ \tau & \text { Maximum specific growth rate } & \left(\mathrm{hr} r^{-1}\right) \\ \tau^{*}=\mu_{\mathrm{m}} \tau & \text { Residence time } & (\mathrm{hr}) \\ & \text { Dimensionless residence time } & (-)\end{array}$

The following gives some typical parameter values [2].

$$
\begin{array}{ll}
\mathrm{K}_{\mathrm{s}}=5,190(\mathrm{mg} \mathrm{COD}) \mathrm{L}^{-1} & \mathrm{~S}_{0}=10,360\left(\mathrm{mg} \mathrm{COD}^{-1} \mathrm{~L}^{-1}\right. \\
X_{\mathrm{i}, 0}=2,810(\mathrm{mg} \mathrm{VSS}) \mathrm{L}^{-1} & \mathrm{X}_{\mathrm{s}, 0}=22,59\left(\mathrm{mg} \mathrm{VSS}^{-1} \mathrm{~L}^{-1}\right. \\
\mathrm{f}_{\mathrm{s}}=0.8 & \mathrm{k}_{\mathrm{d}}=0.015 \mathrm{day}^{-1} \\
\mathrm{k}_{\mathrm{h}}=1.1 \mathrm{day}^{-1} & \alpha_{\mathrm{g}}=0.03(\mathrm{mg} \mathrm{VSS}) /(\mathrm{mg} \mathrm{COD}) \\
\alpha_{\mathrm{h}}=1.88(\mathrm{mg} \mathrm{COD}) /(\mathrm{mg} \mathrm{VSS}) & \alpha_{\mathrm{S}}=1.42(\mathrm{mg} \mathrm{COD}) /(\mathrm{mg} \mathrm{VSS}) \\
\mu_{\mathrm{m}}=0.22 \mathrm{day}^{-1} &
\end{array}
$$

The following gives some typical dimensionless parameters.

$$
\begin{array}{llll}
\mathrm{S}_{0}^{*}=1.996 & \mathrm{X}_{\mathrm{s}, 0}^{*}=145.0857 & \mathrm{X}_{\mathrm{i}, \mathrm{o}}^{*}=18.0475 & \mathrm{k}_{\mathrm{d}}^{*}=0.068 \\
\mathrm{k}_{\mathrm{h}}^{*}=5 & \alpha_{\mathrm{g}, \mathrm{h}}=0.0564 & \alpha_{\mathrm{g}, \mathrm{s}}=0.0426 & \mathrm{COD}_{0}^{*}=10.1788
\end{array}
$$




\section{Author addresses}

1. A. O. M. Alharbi, School of Mathematics and Applied Statistics University of Wollongong, Wollongong, NSW 2522, Australia mailto:aoma093@uowmail.edu.au

2. M. I. Nelson, School of Mathematics and Applied Statistics University of Wollongong, Wollongong, NSW 2522, Australia mailto:nelsonm@member. ams . org

3. A. L. Worthy, School of Mathematics and Applied Statistics University of Wollongong, Wollongong, NSW 2522, Australia mailto: annie@uow.edu.au

4. H. S. Sidhu, School of Physical, Environmental and Mathematical Science University of New South Wales at the Australian Defence Force Academy, Canberra, ACT 2600, Australia mailto:h.sidhu@adfa.edu.au 